\title{
The Influence of Music Training on Children's Cognitive Ability*
}

\author{
Jie Liang \\ Qinghe Campus (School of Mechanical and Electrical Engineering) \\ Beijing Vocational College of Agricultural \\ Beijing, China 102208
}

\begin{abstract}
By analyzing the influence of music training on children's language ability, spatial reasoning ability and mathematics ability, this paper points out that learning music cannot improve the cognitive ability in all aspects of human beings. It is clarified that the degree of improvement of human cognitive ability is affected by many factors, and only a long time of effort can have a stable effect. Parents are advised not to blindly follow the effects of children's extracurricular music training, so as not to undermine the child's autonomy and interest in music.
\end{abstract}

Keywords-music training; language ability; spatial reasoning ability; mathematical ability

\section{INTRODUCTION}

Every parent wants their children to be better. If there is any way to help the child get smart, articulate and excellent in academic performance, many parents will be eager to choose it. If you are walking on the road one day when a person who recruits students for music extracurricular classes advocates that their piano, violin, vocal and other extracurricular classes can make children smart, reasonably claims that psychology has been researched and learned that music can make children articulate, have good sense of direction, and even improve the performance of Chinese and mathematics, and gives examples of many great scientist who can play instruments such as Einstein and other great scientists, will you believe such propaganda? Is there relationship between learning music and getting smart? What aspects will it be effective in intelligence? Can children become versatile as long as they learn music? Will you ask your child to learn a variety of instruments because of this? So how much is the effect of music education in promoting intelligence function?

There are indeed many studies in psychology that use scientific and rigorous methods to explore the impact of music training on human cognitive function, but the results do not all point to positive effects. For this complicated problem, the empirical research related to the review article the impact of music training on cognitive ability published in

*Fund Project: One of the research results of the Humanities and Social Sciences Project of Beijing Vocational College of Agricultural "Application of Ecological Psychological Counseling in Mental Health Education in higher vocational school" (Project Approval Number: 20170321, leader: Liang Jie)
China's authoritative psychological journal Advances in Psychological Science in 2015 made analysis and comparative discussion.

\section{The INFLUENCE OF MUSIC TRAINING ON CHILDREN'S LANGUAGE ABILITY}

Many psychologists believe that language ability is also an important component of human intelligence. For example, Gardner's theory of multiple intelligences includes "language intelligence." People often compare music to a language that expresses people's thoughts and feelings. However, music does have a great correlation with the language ability of brain cognitive function, which is proved by neuroscience on the physiological basis.

In terms of language comprehension, studies have proved that learning music can help children to "listen" more, and children who learn music may also "understand" more, which means that they can not only distinguish that some strange pronunciations of adults may make sense, and they may try to understand what it might mean. In terms of language expression, children who have learned music may even be able to say more, especially for children who have a certain dyslexia or poor reading ability, and the difference in "speaking" is even reflected in foreign language such as English. In addition to oral language expression, children who have learned music are better at spelling and writing.

Will you feel really amazed, and even regret that you didn't learn music when you were a child? You shouldn't be excited too early, because there are two issues that need our attention. First of all, many studies here, including foreign language studies, just prove that children who have already studied music have stronger language skills, which means that there is certain correlation between learning music and language skills, but the cause of this relationship is not proven. It can't be said that music training will definitely improve the children's language ability because it may be on the contrary. For example, children with strong language skills are also talented in music, so they are interested in music and learn music; or there may be other factors that affect both music and language skills, such as the speed at which children accept new things, their ability to understand emotions, and so on. Therefore, we have no reason to believe that we can enhance their language skills by learning music. The second problem is that even though some studies here 
have proved that music training can improve the language production ability and written language production ability of the mother tongue, it does not specify whether the degree of improvement has practical significance. The existing possibility is that through a lot of music training efforts, the child's language ability is indeed higher than other children, but the degree of high is too limited to be mentioned.

\section{THE INFLUENCE OF MUSIC TRAINING ON CHILDREN'S SPATIAL REASONING ABILITY}

Although music and visual space don't seem to be relevant, there are also studies that show that there are mysterious connections between beautiful notes and space. A study published in the international top natural science journal Nature in 1993 showed that it is possible to temporarily improve people's spatial reasoning ability only by listening to Mozart music for 10 minutes. This magical effect is called "Mozart effect", which immediately triggered public discussion and a lot of follow-up research. For a time, people have different opinions on the miraculous effects of listening to music to enhance the cognitive ability. Different studies conducted the music training with different nature and adopted different methods of measuring space capabilities, so the results and conclusions are different. Many of the dissident studies have effectively proved that listening to music is not related to spatial cognitive ability or is only related to a small part of it. For example, only music creation is related to spatial relationship ability; even researchers have recently analyzed the data of published studies about this problem and concluded that the "Mozart effect" did not exist. However, this may also be related to the fact that the time spent listening to music in the experiment is too short. There may be more further research that not only compare the differences between the children who have learned music and those who have not learned music, but also treat the children who have no differences differently by letting some learn music while some do not learn, and then observing if there are differences in the spatial ability of the two groups of children, so that we can better understand whether this difference is caused by the factor of learning music.

Whether or not these critiques are strong enough to persuade the side advocating positive effect, at least we can understand that Mozart music is not an artifact that makes people smarter.

\section{THE INFLUENCE OF MUSIC TRAINING ON CHILDREN'S MATHEMATICS ABILITY}

We have all heard that both Einstein and Holmes can play the violin, so will we think that good mathematics ability is related to music? The results of the study on cognitive ability in mathematics are similar to those of language and space. That is, the nature of music training and the method of testing mathematics ability are different, and the conclusions obtained by various research institutes are not consistent. Specifically, how hard the children tried to learn music, and how many years they can persist in learning, namely the intensity and age of music training have an impact on the result of improving mathematics ability. In different aspects of mathematical ability, such as algebra and geometry, the results vary between different types of mathematical tasks.

That is to say, psychologists do not have a clear answer as to whether learning music can help children improve their mathematics. This is a somewhat complicated issue.

\section{ANALYSIS OF THE EFFECT OF MUSIC TRAINING ON CHILDREN}

Through the above analysis and comparison, it is probably to come to the conclusion that the statement "learning music makes people smarter" is scientific to a certain extent, but learning music does not improve people's cognitive competence in all aspects. Besides, the degree of improvement is also subject to a variety of factors, and it may require a long period of effort to have a stable effect. It seems that the advertisement of extracurricular class that claims that learning music can make children become small genius is exaggerated.

In fact, not only do those people who sell music extracurricular classes in the market deliberately exaggerate the influence of music training on children's cognitive ability for making money, but some informal "science" articles only promote and spread the experimental research that support the positive results related to this issue. If the author does not think critically and blindly praises it in order to attract people's attention or only makes one-sided interpretation without referring to other relevant research results, it may also have a biased guidance in the public's understanding. Teachers of extracurricular classes who haven't had psychology training may also be victims of such guidance. Only after a comprehensive comparison can we have a more objective and clear understanding of this issue. Therefore, it is also recommended that people should maintain a certain degree of skeptical attitude and critical spirit for things that sound very magical, and never blindly follow.

Although music training may not have the magical effect on all aspects of the child's cognitive function, it does not mean that the value of music is greatly reduced. For example, some mothers will listen to light music during pregnancy, some parents will often sing with their children, and some families with conditions may take their children to the concert, etc. These are good art education activities. Although parents may have utilitarian motivation for doing this initially, but it was not necessary to give up these habits because of learning that the educational effect of music on children is not significant after reading this article. In real life, parents must firstly reduce the unrealistic expectations of music training by objectively recognizing the role of music training to make children smart, articulate and excellent in academic performance by learning music. They must first learn to calm down, and don't have too much expectation for making children smarter by using music. 


\section{CONCLUSION}

So how should we weigh and make decisions about whether or not to let children learn music extracurricular? In general, it is recommended to provide the child with appropriate additional music learning opportunities if the child is interested and has some autonomy. However, it is important to consider the child's musical talent and avoid putting too much stress to the child or forcing the child too much, because if the child loses the autonomy of growth and interest in the study of music in order to increase the cognitive ability, this approach will neglect the essentials. After all, in addition to some external utilitarian value, music training has many other important intrinsic values. It is acceptable that children make no progress in cognitive ability. We can regard it as self-entertainment to cultivate sentiment and moral character, shape temperament and get pair of ears that can appreciate beauty.

\section{REFERENCES}

[1] Wang Hang, Jiang Jun, Jiang Cunmei. The impact of music training on cognitive ability. Advances in Psychological Science, 2015, 23(3), 419-429. (in Chinese)

[2] Wang Hang, Jiang Jun, Jiang Cunmei. The impact of music training on cognitive ability. Advances in Psychological Science, 2015, 23(3), 419-429.

[3] Bernstein, E. (2014). How You Make Decisions Says a Lot About How Happy YouAre. The Wall Street Journal.

[4] Hodges,D., \& Sebald, D. (2011). Music in the human experience: An introduction tomusic psychology. New York: Routledge.

[5] Levitin,D. (2010). The world in six songs: How the musical brain created human nature.London: Aurum Press.

[6] Juslin, P. N., Harmat, L., \& Eerola, T. (2013). What makes musicemotionally significant? Exploring the underlying mechanisms. Psychology of Music. 